\title{
Brief Communication
}

\section{Why should students of the different discipline in Jimma University (JU) be involved in community based education (CBE)?}

\author{
Prof. Mekonen Asefa*
}

Community based education was introduced as a learning and teaching strategy for an innovative education in the 1980s in the then Jimma Institute of Health Sciences (JIHS). CBE was adapted for an innovative education strategy by considering the local societal organization. People at grassroots level were organized by 'kebele'-the smallest administrative unit in the country. This was a structure where people were organized for socio-economic development. Understanding the local potential for learning in a community setting, and whereby both students and society could benefit from each other, CBE was introduced. CBE has three different programs. CBE was a novel initiative to our setting to introduce problem solving, student centered learning process for an innovative education, (Asefa 2000).

The learning process follows, problem solving which comprises convergent and divergent approach. The different programs of CBE process follows: site selection, developing survey/study tools, data collection, processing and analysis of data, drawing of action plan, implementation and evaluation by involving the community and different development stakeholders, (Asefa 2000, Asefa 2008).

Through these processes students acquire the following generic skills.

- Numerical application: through collected data processing, analysis, critical and hypothesis testing

- Communication: students during their various community attachments carry out various activities by talking, discussing and advocating with different sections of society, development workers, community leaders, local governments. Based on survey/study findings, they prepare different reports to the different stakeholders; organize workshops for learning and advocacy. These tasks enhance learners oral and writing communication competencies.

- Team work: students are assigned in groups in most CBE programs. As a group/team they learn from each other, practice conflict resolution, appreciate difference of opinion, be open minded, built on each member strength for synergetic effect.

E-mail: mekonen_asefa@yahoo.com 
- Problem solving: the identified issue/problem during the survey/study are to be attempted through:

- Convergent approach, where students look for one appropriate solution

- Divergent approach, where students thinking is challenged and stimulated to look for different and new solutions through an imaginative and creative higher order thinking

- Self-management: during all the above engagement and process students are encouraged to learning by doing to enhance student-centered learning. This implies identifying learning gaps, setting learning objectives, time budgeting. Again this enhance the learners potential of learn how to learn

- Information technology: this is a skill which grew as the resources in JU improve. This is the area which students improve the use of computers during data entry and analysis, internet brows-looking for relevant and up to date literature, accessing and retrieving electronic data, using power point presentation for the above mentioned different forums.

Again students from each discipline are encouraged to undertake a senior research projects. In this endeavor students follow problem solving steps from data collection to looking for solutions. This engagement stimulates the learner's thinking to theorize, hypothesis, reflect, create.

Thus, as illustrated above, through CBE students develop the different generic skills which work across disciplines. Again students develop higher order learning by passing through from simple fact gathering to analysis, synthesis, application, and looking for new/creative solutions in a step by step and spiral form. 
This is depicted in figure 1, below.

Figure 1. Higher order learning verbs in spiral form from simple to complex

Theorize, hypothesis

Reflect, create

Explain, analyze

Solve problem

Describe, classify

Compute, illustrate

memorize, identify

count, match

From low to higher order learning

Hence, $\mathrm{CBE}$ is a learning process which greatly addresses the current issues of higher education both at national and international levels (HERQA 2007, higher education academy, Biggs and Tang 2007, Diamond 2008):

- Generic skills mainly comprising: numerical application, communication, team work, self-management, problem solving, information technology

- Higher order/deep/complex learning: through the different attachments and endeavors the learners follows the learning process from simple facts gathering and identification to a higher order/complex leaning in a spiral form as depicted in figure 1, above.

This is a unique virtue of JU students which prepares them for self-learning, to work in a new and unusual environment, employability, self-employment in this cut-throat competitive world. Giving an added value to the learner. Above all, this a preparation for higher order/ complex learning in this complex and fast moving world. 
And this is why JU is involving all students in the different discipline in CBE which is sine qua non for higher education. This is an area of Excellence for Jimma University.

\section{References}

Asefa M. et al. community-based medical education: the experience of Jimma University in Ethiopia. Ethiop. J. Health Dev. 2000, 14: (special issue).

Asefa M. Imaginative, innovative and creative curriculum (IICC). Ethiop. J. Educ. \& Sc. 2008; 3:107-119.

Higher education relevance and quality agency (HERQA). HERQA profile, publication series-011,2007

Higher education academy http://www. Heacademy.ac.uk

Biggs $\mathrm{J}$ and Tang C. teaching for quality learning at university. Berkshire, McGraw-Hill, 2007.

Diamond RM. Designing and assessing courses and curricula. San Francisco, John Wiley \& Sons, 2008

Bloom BS. Taxonomy of educational objectives hand bool: cognitive domain 1956 


\section{Corrigendum}

\section{Dear readers: Please substitute the correction of the chart on page 119 of} Vol. 5 No. 1 Sept. 2009 issue. This is depicted in figure, below.

Figure 1. Higher order learning verbs in spiral form from simple to complex

\begin{tabular}{llll} 
& & & \multicolumn{1}{c}{$\begin{array}{l}\text { Theorize, } \\
\text { hypothesis } \\
\text { Reflect, create }\end{array}$} \\
& & $\begin{array}{l}\text { Explain, } \\
\text { analyze } \\
\text { Solve } \\
\text { problem }\end{array}$ & \\
& $\begin{array}{l}\text { Describe, } \\
\text { classify } \\
\text { Compute, } \\
\text { illustrate }\end{array}$ \\
$\begin{array}{l}\text { Memorize, } \\
\text { identify } \\
\text { count, match }\end{array}$ & & & \\
\hline From & low & to higher & order learning
\end{tabular}

Hence, $\mathrm{CBE}$ is a learning process which greatly addresses the current issues of higher education both at national and international levels (HERQA 2007, higher education academy, Biggs and Tang 2007, Diamond 2008):

- Generic skills mainly comprising: numerical application, communication, team work, self-management, problem solving, information technology.

- Higher order/deep/complex learning: through the different attachments and endeavors the learners follows the learning process from simple facts gathering and identification to a higher order/complex leaning in a spiral form as depicted in figure 1 , above.

This is a unique virtue of JU students which prepares them for self-learning, to work in a new and unusual environment, employability, self-employment in this cut-throat competitive world giving an added value to the learner. Above all, this is a preparation for higher order/ complex learning in this complex and fast moving world. 